\title{
Scaling-up local foods: Commodity practice in community supported agriculture (CSA)
}

Article in Journal of Rural Studies · April 2014

DOI: 10.1016/j.jrurstud.2014.01.001

CITATIONS

18

1 author:

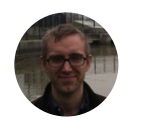

Eric Nost

University of Wisconsin-Madison

8 PUBLICATIONS 28 CITATIONS

SEE PROFILE 
Scaling-up local foods: commodity practice in community supported agriculture (CSA) Eric Nost

Journal of Rural Studies 34, 152-160

http://www.sciencedirect.com/science/article/pii/S074301671400014X

nost@wisc.edu

No figures

\section{Introduction: Know Your Farmer, Know Your Food}

Advocates for local foods - from individual consumers to government agencies - rally around the idea that knowing who grew their food and how can be means for enacting social change and improving the environment. The United States Department of Agriculture (USDA) has codified this sentiment by placing a diverse set of the agency's initiatives - from greenhouse cost-shares to grants for beginning farmers - into an umbrella program named "Know Your Farmer, Know Your Food" (USDA 2011). USDA has national ambitions with the program, yet the acts of knowing farmers and knowing food vary greatly from farm to farm. In this paper, I provide a way of explaining how they come to be different and argue that demonstrating why they differ should come before judging whether different ways of knowing are positive or negative for social and ecological change. I describe the varied practices that farms perform in order to give their products market value as embedded in a specific socio-ecological context (Hinrichs 2000). My main point is to advance an awareness of hybridity in local foods institutions (Harris 2009; Mount 2012).

Compare three community supported agriculture (CSA) farms. The first farm's truck driver drives four hours from the farm to the share pick-up site on the edge of a major Midwestern metropolitan area. If shareholders' produce boxes are especially full, it may be that the farmer had to scramble to make them look that way and perhaps called upon one of the area's Amish farms to supply some spinach. Shareholders may not be able to tell just from looking at 
the box or reading the newsletter, but the produce could be from several places: those neighboring farms, Amish farms farther out, or grown on the farm itself with intern and immigrant labor.

The second CSA's pick-up site is a community center in the middle of a small Midwestern city. The farmer has traveled half an hour to get there, only a little bit farther than sharers. As with the first farm, shareholders may not be able to tell just by looking at their food, but if they asked, the farmer would tell them how it was grown (on his farm). In fact, he might just complain about his high cost of labor or the difficulties of wrangling volunteers.

Shareholders arrive on the third farm to pick up their grocery sacks worth of veggies after a 20 minute drive out of town. The farmer - or her elementary school age daughter - explains the ins and outs of free-range chickens to those who are curious about the wandering flock. The farm's volunteers have long since headed home for the day, but most of the harvesting and packaging of shares was a product of their effort.

All three farms seem to present the same story. In each case, sharers receive vegetables from a farm by paying a fee up front and picking up the farm's weekly offering. They also differ in important ways. In two, shareholders meet the farmer; in another they read the weekly emails. In the first, the produce comes from several places; in the other cases, it was grown right on the farm. The farms' work is constituted by scalar relations of production and exchange across different spatial extents and levels of organization. But how and why have they come to be different?

I answer that they practice local foods differently. This is a response to recent commentaries on emerging contradictions in US local food systems. Anthropologist Laura DeLind $(2011 ; 1999)$ or the farmer-activist Elizabeth Henderson (2012) would contend that the 
first farm has lost sight of the point of local foods by circumventing a direct exchange between eater and grower and incorporating other farms' produce into the share, as well as by delivering "local" vegetables to shareholders over 200 miles away. However, in order to even begin to answer the question of whether scaling-up is misguided, we should first understand how farms come to scale. Their hybrid approaches to the problems of making a market for their goods show us how the practices of "scaling-up" local foods result in various scales of production and exchange in CSA. These different practices are not necessarily incongruent with the aims of local foods advocates.

I draw upon experience working on the farms described above to elaborate three key moments of CSA farming that commentators like Henderson and agro-food scholars are concerned about when it comes to scaling-up: 1) the employment of different kinds of labor; 2) working within the seasons; 3) the management of sharer expectations. As what I call commodity practice, farm decisions about these factors produce differently scaled local food commodities. Commodity practices are why farm operations look different: some engage in direct exchange and grow their produce on the farm, while others aggregate from partners; some are labored on by sharers or volunteers, while others include more hired help. As CSAs and other local foods institutions like food hubs grow and evolve, a look at commodity practices can shed light on and confound some of the apparent contradictions in scaling-up. How these commodity practices have changed over time can be seen by first taking a look at some of the main issues CSA practitioners have faced in creating the new institution.

\section{Literature Review}

\subsection{The CSA Story}

The history of CSA in the US is well-recited (Henderson and Van En 1999; Lyson 2004; 
McFadden, nd). In the mid-1980s two farms - Indian Line Farm and Temple-Wilton Community Farm - in New England started producing vegetables for local customers. They held in common the notion that production would be sharer-oriented and that sharers should shoulder some of the upfront seasonal costs. The risk-sharing emphasis of CSA spread through personal contacts, conferences, and books (Henderson and Van En 1999) but as Elizabeth Henderson spelled out by the late 90s, CSAs varied greatly in response to the unique shareholder desires and specifics of local land availability and tenure options. Henderson (with van En 1999) pointed out differences between CSA models, especially between multi-farm, subscription, and member-driven CSAs. She noted that farms like Angelic Organics (of The Real Dirt on Farmer John fame) and Full Belly (the CSA Michael Pollan subscribes to) sustained large memberships, but still offered its sharers opportunities to connect to the farm and asked sharers to participate in hedging the risk of farming. More recently (2012), however, she laments the rise of new ventures like regional aggregators and distributors, which deliver produce - sometimes out of season - from several farms. They do not require that sharers participate in a community that makes any sort of upfront contribution to the success of the participating farms. They do not have to volunteer for farm labor, for instance.

Henderson's observations are not the isolated concerns of a long-time activist. Many academic students of food have found that the economic and social goals of local food projects often exist in tension, as with community-building versus profit-making in CSAs (Cone and Kakaliouras 1995; Hinrichs 2000; DeLind 2003; Lang 2010), commitment to agrarian ideals versus scaling-up in the organic sector (Allen and Kovach 2000; Guthman 2004; Fromartz 2007; Rigby and Bown 2007) and social justice versus earning a livelihood in farmers markets (Alkon 2008). In two recent papers, DeLind (2011) and Mount (2012) focus specifically on tensions in 
how local foods endeavors scale-up to expand their reach.

DeLind (2011) takes issue with the way the benefits of local foods have been marketed and how local foods endeavors have turned into "instrumental" rather than local, "contextual" projects (280). Her concerns are three-fold. Locavorists, she explains, champion tactics like 100mile diets and in so doing emphasize an individual and consumer-oriented relationship to local foods. Her second point follows; she laments that local foods have become something to buy from a multinational corporation like Wal-Mart, at the expense of building place-oriented community. Finally, she resists the idea that local foods activists should look to individual, national figureheads like Michael Pollan as primary sources of thought and inspiration. She argues for activists to (re)turn their attention to particular community-centered circumstances and opportunities. Her calls for a reconsideration of movement values and for heeding "diversity, necessity, and cultural pluralism," (278) are trenchant, but the implication is that there is something about the local as a more direct exchange and relation between farmer and consumer that stands to benefit from activists' renewed attention.

Mount (2012) engages with similar questions of how to continue to grow local foods systems, but with less of an antagonism toward economically, politically, and ideologically scaling them up as DeLind. He takes the apparent paradox in scaling something so tied to the local and re-thinks the binaries (e.g. conventional/alternative) and assumptions that gird the paradox. While most commentators are quick to point to a direct exchange between producer and consumer as the centerpiece of what makes local foods "win-win-wins", he argues that paying attention to an already existing diversity of institutions and types of economic interaction opens up a "reflexive" (DuPuis and Goodman 2005) way of seeing local foods as already operating beyond limited, purist notions of direct connections (see also Hinrichs 2000; Trauger and 
Passidomo 2012; generally on diverse economies, Gibson-Graham 2006). He writes that treating "direct exchange itself as fundamental to added value within LFS [local food systems] treats [the] complexity" of local foods-focused interactions as an afterthought (114). Abiding by this diversity also helps to overcome associating any scale or locality with any particular outcome (Born and Purcell 2006). Here I try to flesh out Mount's discussion by using the concept of "commodity practice" to understand the complexity of local foods production and exchange.

\subsection{Commodity Practice}

DeLind and Mount might as well have been talking about the commodification of local foods when they respectively lamented or deconstructed the scaling-up of local foods. What Marx considered a commodity was anything produced for someone else and exchanged for an equivalent (Marx 1976). For him, the value of a commodity was a social creation, one centered on the bringing of commodities into relation with another through exchange. With this in mind, we should ask, where and how is the ("added") economic value of local foods produced? Researchers who followed David Harvey's (1990) rallying cry to investigate commodity relations have asked several questions that are pertinent here. How is nature commodified and what sort of abstractions from its social and ecological context are necessarily made? (Cronon 1992; Castree 2003; Robertson 2011) How are meanings and narratives commodified? (Cook and Crang 1996; Guthman 1998; Bryant and M.K. Goodman 2004; M.K. Goodman 2004)

It takes what I call commodity practice to turn local foods into something with economic value in CSA. Businesses, regulators, producers, and consumers apply various kinds of labor to abstract objects from the context of their production with the goal of making these objects exchangeable-(Robertson 2011). Farmers, regulators, consumer groups, and sellers take measures to show, for instance, that their tomatoes are local, organic, nutritious, or seasonal. These are 
both representational and material practices (Robertson 2000). Consider, for example, CSA newsletters whose authors bracket the questions of what kind of labor grew the share produce and where. Another example is when farm volunteers sling dirt off of onions to make them appealing to sharers, or, when the decision is to leave dirt on them to make them look fresh or recently picked. The character of local foods is an achievement made by the practice of actors who do different kinds of work to make them local, seasonal, or ecological.

The literature shows that there are three elements that are the most important aspects of CSA farm practice: managing labor, dealing with seasonality, and responding to shareholder expectations. In their take on the agrarian question, Mann and Dickinson (1978) argued that the the capitalization of agriculture and, specifically, the employment of wage labor were made difficult by the seasonal nature of farming, plants' unique ability to assemble themselves, and the immobility of land (but see also Mooney 1982; Henderson 1998). What Mann and Dickinson illustrate is that the supply and application of labor to grow crops for market are unique challenges farm enterprises have to account for. CSA labor forms are indeed varied (Henderson and Van En 1999), manifesting as farmer-only (Janssen 2010), sharer volunteer labor (Cone and Myhre 2000), as wage labor (Janssen 2010), or more typically, as a mix of seasonal hired, intern, and volunteer help (Galt et al. 2011). As Janssen (2010) found out, the deployment of labor matters for what can and does get done on a CSA farm and what sort of exchange relations are possible. Even non-wage forms like volunteer labor can still "articulate" with, or be a part of, commodification in farming (de Janvry 1980; Wolpe 1980; see also Gibson-Graham 2006).

The second commodity practice concerns seasonality: both the climate conditions which change throughout the year (i.e. winter, spring, summer, and fall) and the weather patterns within a given season (i.e. wet or dry years). Local foods imply eating in pace with the seasons (see for 
instance any of the popular manifestos, e.g. Nabhan 2002, Pollan 2006). On the production side, CSA farmers - in the US Midwest at least - are limited by what crops they can grow in any given season. Seasonality is not a fixed definition. For instance, farmers can use aids like black plastic to encourage production earlier in the year. More generally, as Henderson (1998) and Guthman $(1998 ; 2004)$ have noted, nature's obstacles are at the same time opportunities. Henderson (1998) showed how seasonal rhythms in Californian agricultural production presented an opening for finance capital to lend money to farmers before they could cash their crops in. In CSA, seasonality can be an opportunity if not for financial capital, then for entrepreneurial farmers. Seasons can be extended, for instance, through hoophouses or developing new kinds of share types, like for winter storage crops. ${ }^{1}$ Rather than an absolute and limiting barrier, deciding when local foods can be grown and sold and with what tools is a commodity practice.

Finally, commodity practice involves handling sharer expectations about the qualities and quantities of farm produce they receive: things like the degree of pest damage and its organicness or local-ness. Conventions of quality are well researched in local foods research (Holloway and Kneafsey 2000; Jarosz 2000; Murdoch et al. 2000; Andreatta and Wickliffe 2002; Perez et al. 2003; Sage 2003; Goland 2008; Smithers et al. 2008). The main finding here is that those conventions are not innate and universal but are instead continually negotiated between grower and buyer. My point here follows from that conclusion. Ideas about produce characteristics are negotiated between farmer and sharer, but it is a practice the farmer has to cultivate. It is a choice about how much to educate shareholders about farm operations and in that sense it is a commodity practice.

Labor, seasonality, and expectations are commodity practices that are also practices of scale. The scale question in the local foods literature is well-tread (e.g. Winter 2003; DuPuis and 
Goodman 2005; Born and Purcell 2006). Born and Purcell (2006) in particular ask us to avoid the trap of assuming local means better, since it has no fixed definition. They argue that scales like the local or global are socially defined rather than lines already given on a map. Scales are the effects of particular actors pursuing particular kinds of relations (Mansfield 2005; Fraser 2010; Harris 2012). Different practices of managing labor, seasonality, and expectations lead to different ways of scaling the relations of production and exchange that constitute a CSA farm. These scalar relations are defined by both the spatial extent of farm operations and the scope of organization it takes to get produce from grower to eater ${ }^{2}$. When DeLind (2011) worries about Walmart's foray into scaling up local foods, it is the company's global reach and its convoluted supply chain that concern her. Likewise, Henderson's (2012) skepticism toward CSAs that aggregate produce from other farms is directed at the extensive distribution capacities of these CSAs - the number of steps from farmer to eater - as well as the fact that they encompass spaces and ecologies that extend well beyond the farm grounds themselves.

Scalar practice is hybrid. The use of wage labor, for instance, allows more farm work to be done, which possibly grows the scale of the enterprise by increasing the number of acres in production. Wage laborers may also free up time for farmers to conduct more sales that do not rely on a direct link between grower and eater. Likewise, choices about growing and distributing crops seasonally - like utilizing a greenhouse - are a kind of scaling of social and ecological relations. Greenhouses may allow for greater production within the CSA or through other indirect markets venues like grocery stores, but intensify cultivation within the space of the farm. Finally, how farmers manage expectations about locality and other produce qualities scales the CSA. Spending more time educating sharers may limit what other work can be done, but it also fosters more direct connections between grower and eater. In these commodity practices, scaling 
is never clearly "up" towards indirect and extensive methods of production and distribution, nor "down" to direct, interpersonal exchange centered on one farm space.

To briefly review: CSA involves a commodity practice of managing labor, seasonality, and shareholder expectations. These may not be every CSA's only practices, but as the literature suggests, they encompass many of the most important aspects of farming. Farmers' other choices - for instance, regarding the use of farm implements and other technology - will often be means to the ends of these three practices. Different decisions about labor, seasonality, and expectations shape how farm operations and their scales differ. These scalings are hybrid, and hence are questions to be answered empirically. I turn now to understand how commodity practice plays out in three Midwestern CSA farms, first describing my methodology.

3

Methodology:

Researching

CSAs

Participant observation and interviews are useful to understand how commodity practice plays out on the ground, particularly in institutions like farmers markets (e.g. Alkon 2008) or CSAs (e.g. Janssen 2010) that involve both production and consumption. A good portion of the research on local foods and CSAs is qualitative and often mixed-method (e.g. Galt et al. 2011; Perez et al. 2003), but these sorts of studies do not necessarily include the sort of day to day "inspection of the ordinary" that can provide an understanding of what farm operations look like beyond statistics. My research was conducted over five growing seasons between 2008 and 2012. Methods included participant observation employed as either an hourly worker or intern on three different Midwestern CSA farms and interviews with farmers and consumers at a small town farmers market. These methods allowed me to understand farmers' and consumers' stated motivations as well as their actual practices. Asking a farmer directly what they think about the prospects of local foods may solicit a rosy response, while paying attention to practices will often 
paint a different picture.

Here I present the results in terms of three case studies of the CSA farms, as do many other CSA studies (e.g. Feagan and Henderson 2009; Janssen 2010; Lang 2010). My method is to draw from the participant observation to tell stories about each case that are illustrative of commodity practice on the farm. The goal of a case study approach is not to achieve some sense of representativeness but to write narratives that link the particular operation of each farm enterprise to broader trends and forces in local food production. The purpose is to develop themes that resonate (see Burawoy 1991). The deployment of labor, the seasonality of food production, and the management of consumer expectations about produce quality are all components of commodification well-known to agro-food scholars, but I show how all the themes matter specifically in the context of different approaches to doing CSA. I first return to the three CSA farms we opened with to think in more detail about how their operations diverged. I provide an overview of each farm's operation during one particular season by walking through the various steps it took to get the produce from field to packing shed to shareholder

\section{Results: The Work of CSAs}

\subsection{Lazy River Farms ${ }^{3}$}

- Lazy River Farms (LRF) is nestled within the hills and valleys of southwestern Wisconsin. This part of the state has historically been home to alternative food endeavors, including organic farms, co-ops, and early CSAs. The region is currently witnessing a growth in operations which aggregate produce from multiple area farms and distribute to nearby metropolitan areas. LRF is a relatively new endeavor. In the late 2000s, the owners purchased the old piece of dairying ground and built the only structure on it, a pole barn. 


\begin{tabular}{|c|c|c|c|c|c|c|}
\hline Farm & State & Season & Shares & Distance to market & $\begin{array}{l}\text { Other } \\
\text { markets }\end{array}$ & $\begin{array}{l}\text { Other } \\
\text { sources }\end{array}$ \\
\hline LRF & WI & 2010 & 500 & 225 miles & $\begin{array}{l}\text { Food service } \\
\text { vendors }\end{array}$ & $\begin{array}{l}\text { Area farms; } \\
\text { auction }\end{array}$ \\
\hline SRCSA & IA & 2011 & 180 & 20 miles & $\begin{array}{l}\text { Direct sales of } \\
\text { meat }\end{array}$ & Partner farm \\
\hline$\overline{\text { STF }}$ & KY & 2012 & 60 & 10 miles & Restaurants & $\begin{array}{l}\text { None } \\
\text { currently }\end{array}$ \\
\hline
\end{tabular}

Table 1. Key statistics for three CSA farms.

Production and distribution on most CSAs are centered on a weekly schedule. On either

Monday or Thursday afternoons during the 2010 season, LRF shareholders would receive newsletters anticipating the following day's produce pick-up. In these newsletters, the farm owner communicated a literally down-to-earth knowledge which established a trustworthy main character who, for instance, knew when and when not to harvest basil:

"Greetings from your soggy farm. Another day of rain, it's been going steady since about 10 this morning. Luckily we had almost everything harvested; except the basil for the half shares. If we harvest basil when it's wet it turns black and slimy." (email, 31 August 2010)

Due to rains like the ones mentioned in the newsletter, many of the vegetables supplied for the CSA that year were not grown on the farm itself, but purchased from nearby farmers. A lot of crops that farm workers had planted were either not at all or barely salvageable. Instead of asking members to accept this loss, the farm turned to two sources of Amish produce. The first source was located about a 15 minute truck ride away. The LRF farmer and these Amish farmers would discuss what could be bought or sold each week - there was no set contract. During the 2010 season, LRF also worked with one of these farms to receive some of its transplants as the farm did not have its own greenhouse. The owners were, however, wrapping up an agreement with the National Resource Conservation Service (NRCS) to receive a greenhouse at a greatly reduced price as part of the USDA's season extension program. ${ }^{4}$

The other primary off-farm source was a produce auction about half an hour away. The 
auction extended the links between the shareholder and the grower. Most shareholders had a relationship with LRF consisting of newsletter updates and interactions at pick-up sites with the farmer and workers. The farmer, in turn, knew and trusted the auction manager, who would bid on items for the farm from Amish growers whose practices he knew and trusted. Other nonAmish farms made regular contributions of items like eggs, while the farm called upon yet another set of non-Amish farms and aggregators who purchase and re-sell produce from multiple farms. Though the main partner Amish farms were sometimes mentioned in newsletters the auction and others were not. Purchasing produce for the CSA from these sources was costly for the farm and frustrating as well. The owners had wanted this season to be the first where they did not have to rely significantly on other farms. It cut into funds that were to have been spent repaying the debt on their land.

Because every week enough of the farm's produce was coming from other farms and since the farm had almost 500 shareholders, a lot of the work that year was dedicated to packing sharers' boxes. The farm's labor consisted of a seasonal average of six hourly workers and six salaried interns. Two days out of the five day work week were dedicated specifically to the task of putting produce in the boxes and loading shares onto the refrigerated truck in preparation for the two drop-off days. Many of the hourly workers were migrants who had previous farming experience. One couple, for instance, had worked on organic farms in California as well as back home in Mexico. The husband was familiar with farm machinery and was charged with the majority of the tractor work. The hourly workers tended to work in the fields while the interns organized the harvest and packed boxes.

Packing boxes was itself an intentional choice for the CSA farm as other subscription CSAs allow members to pack their own items. ${ }^{5}$ Since the share boxes had to be delivered four 
hours away and because there were twenty pick-up sites, not packing individual boxes would have been a logistical nightmare for the farmer. Even in choosing to pre-pack boxes, some farms do try to accommodate individual preferences and requests, though LRF mostly did not. Moreover, splitting the shares into full and half sizes can prove difficult if the half shares are done on a weekly basis (some farms do a half share that is the same size as the full but comes every other week). It requires decisions about how much to give the half share in relation to the full share.

The wet summer greatly limited on-farm harvest of many crops so that for some crops there was only enough of, say, chard to fill only some boxes in any meaningful amount. During the week of the newsletter quoted above, basil was likely to be harvested only for full shares. Throughout the season, the lack of on-farm produce in the right quantity and quality demanded difficult accounting on the part of farm staff. One week midway through the season, the farmer decided to allocate broccoli - a crop in short supply - to some drop off sites and not others. He hoped to make up for it the following week and ultimately did, but it required interns to note and recall the change and it required extra effort to pack the truck so that specific boxes went to specific sites. In an extreme case, on one packing day the farmer decided to take the time after having boxed up shares to send out an email correcting the newsletter's prediction of what would be in the full size. On most weeks, he edited newsletters at the last minute before packing to make sure shareholders received what they expected.

Significant attention was directed toward ensuring the aesthetic integrity of the produce. The farmer communicated to staff the expectations of shareholders for picking and preparing visibly clean produce. These expectations ultimately translated into staff altogether avoiding harvesting most bug-damaged leafy crops as well as thoroughly washing dirty root crops, like 
beets, radishes, or carrots. The expectations were not always successfully translated because of linguistic barriers or just simple misunderstanding. Sometimes workers would go too far in their struggle to provide beautiful produce. In the most tense example, the farm crew decided to cut off the small roots of hundreds of celeriac that had been harvested instead of just slightly trimming them. The farmer, upon returning from the field to the wash station in the barn, was upset because the crew wasted time that could have been spent on more pressing tasks. The roots were also weight that could no longer be charged to the customer.

\subsection{Silver Road CSA (SRCSA)}

The second farm differs from the Wisconsin farm in many ways. SRCSA farms vegetables and pastures sheep in the rolling hills of eastern Iowa. It is an older operation in existence for over a decade and was one of the first of what is now many and continually more farms in the area. The CSA's relatively long-term existence afforded the farmer a degree of influence with shareholders. There were a number of returning members who trusted the farmer to provide the sorts of production practices that they valued. The farmer noted that he had been able to successfully educate his membership over time on what quantity and quality of produce he could and could not provide over the course of a season. Yet he also lamented that there were some aspects of the CSA's operation, like the amount of labor it took to set up irrigation lines on the black plastic, that he found he was still unable to effectively communicate to many members. There were also some practices that remained beyond the farmer's attempts at education. One harvest day in June, farm workers and volunteers spent more than half of the day taking off dried leaves on green onions, washing dirt off them, and cutting their roots. That day and other times when green onions were in the share, pulling and cleaning them accounted for more labor time than any other single task. Instead of convincing sharers to accept onions with some dirt on them, 
the farmer was resigned to cleaning them and had come to expect the effort it took.

The farmer's labor supply was comprised of a variety of skill types and levels. Shareholders and AmeriCorps members provided volunteer-labor which amounted to a regular and substantial component of the week-to-week operation of the farm. A group of shareholder volunteers came most every Monday to prepare the harvest, especially washing vegetables. AmeriCorps volunteers would do larger or more production-oriented tasks such as setting up tomato cages, building a berm around the greenhouse, or starting seedlings. Still, much of the day-to-day labor of weeding was done by the hourly staff or the family members who worked regularly or once in awhile on the farm.

The farmer dubbed himself "a social worker, not a horticulturalist" and this attitude was reflected in his approach to dealing with farm helpers and the harvest. Though a decade plus of managing the CSA had taught him a great deal about how to handle plant and insect pests on the farm, he retained an ethos of practice driven more by his former career as a social worker than any formal knowledge of farming. Many volunteers took home a share's worth of vegetables for their work though some people volunteered anyway without receiving vegetables. Several shares were provided free of charge to low-income support organizations. One week halfway through the season, the farmer and a staff member sought out and donated a bumper crop of garlic scapes, popular in Asian cuisine, to area Korean church groups.

What volunteers and paid workers did not do was pack boxes for shareholders. Instead, SRCSA organized pick-up sites where members brought their own bags to fill with the designated amount of each crop. For some crops, like squash, harvesting meant picking all of what was ready and then allocating the harvest between all sharers. For other crops, like lettuce, the farmer would determine a set amount in advance (e.g. one head). Some produce would be 
bagged, like potatoes or lettuce, but most often it was just placed in a cooler. The fact that the farm was able to bag even some of the produce, especially the lettuce, was possible largely because one of the staff had an injury which prevented them from doing much harvesting.

A typical crop plant in the fields at SRCSA would have been started in one of two places: at the farm's greenhouse or at one of the CSA's partner farms. The farm had three permanent greenhouse structures in addition to several old dairying barns and hog sheds that had been repurposed for activities like drying garlic. A hoophouse on cement was used for starting seedlings for transplant. There was also a hoophouse with wheels positioned on tracks so that it can cover different ground over the course of the year. The farmer recently acquired it through the NRCS season extension program.

SRCSA partnered closely with another CSA about 20 minutes away, which provided SRCSA with its sweet corn and potatoes during the summer. Sometimes SRCSA would share crops like squash when the other farm had not been able to harvest enough or had been set back by the weather. Another farm did fall crops for the CSA and yet other partners provided bread for sharers. These were mainly non-formal agreements, but the farmer was beginning to feel like it might be necessary to formalize them in the future. He is very skeptical of the idea of sourcing produce from an auction because he would likely be unable to tell his customers how it had been grown.

\subsection{Sugar Trails Farm}

This ten-acre farm is located in the Bluegrass region of Kentucky amidst horse farms

often over 100 acres in size. Here, money from the state's part in a major lawsuit against tobacco companies has been set aside to fund new agriculture initiatives, many of which have fostered local food production and infrastructure projects. The CSA has been up and running for about 
five years, but the farmer notes that each season continues to be a learning experience in making the farm profitable, managing pests, and finding and keeping customers.

When the CSA operation was new the farmer found herself having to buy vegetables from nearby produce auctions to supplement the share. She lamented not being able to know much about how the crops she was buying and providing for her shareholders were produced. Now she is in the position to have new CSAs buy directly from her. She takes pride not only in being able to provide her customers with the fruits of her own labor but being able to help other local food entrepreneurs.

On-farm production is bolstered by both a greenhouse and a hoophouse. Both are used intensively to grow items for both the CSA and for other markets. Like LRF, and SRCSA, the STF farmer worked with her local NRCS agent to get the hoophouse through its program. She has plans to acquire another hoophouse through the program, a small one for seedling production. The farm family currently starts seeds in a spare bedroom in their on-farm house.

The majority of shareholders visit the farm in order to pick up their shares. The farmer values having sharers pick up from the farm because it provides an opportunity to educate her shareholders about the farm's practices and produce. Starting in 2012, however, the farm is making a delivery of over a third of the shares to a nearby cooking school. Because many sharers are picking up there this year, the farmer decided to switch from a "take $\mathrm{x}$ of $\mathrm{y}$ crop" process similar to SRCSA 's to individually bagging each share. She felt unable to police the off-site pick-up and has had problems in the past with members taking more than their share. This change produced two difficulties for the farm crew. First, the farmer had to decide whether or not - and how - to incorporate sharer's personal preferences. Previously, she had let customers choose what kind of herbs they got when they picked up their share. Now she has to request 
preferences over email, add them to an Excel spreadsheet, and then put the right herb into each bag to be delivered. She does on weeks she feels up to it or remembers to do it.

The second difficulty in the shift to individual bagging is that the crew had to figure what worked well to pack produce what was simply not worth the time. The labor that goes into weeding, harvesting, and packing for the CSA as well as for the farm's other markets is performed by a variety of people: the farmer's own family, volunteers, and part-time wage staff. Because the farm is dependent on the volunteers' help in harvest, the farmer tries to get two days of harvesting done in the one day a week that volunteers are able to come. This means that some produce sat overnight until delivery at the cooking school or on-farm pick-up the following day. Each week early in the 2012 season the crew struggled through questions like: do beets need a wet paper towel covering them to keep them fresh over the two days? Will sharers care? For the most part, the farmer was out in the field harvesting and left packing decisions to volunteers. They wanted to provide sharers with quality produce, but they also were not going to overthink it. A negative comment left by one former member on a CSA review website (LocalHarvest.com) was a topic of much conversation throughout the season. The volunteers had responded to the review, defending the farm. Their attitude toward sharers was that they should appreciate the farm's efforts, even if they didn't get everything right all the time.

One episode of a sharer caring about the quality of the CSA's produce especially drew the attention of the crew. A new shareholder called the farm after one pick-up to say that he had found mouse droppings in his lettuce. The farmer realized that he had meant caterpillar feces, but the sharer was still disgusted and demanded a refund for the remaining weeks of the share. The farmer was able to convince him to instead visit the farm to learn more about the operation and stay on. Most of the farm staff reacted intolerantly to the customer's demands. As one volunteer 
put it, to much agreement, "it's like I always say, we provide the dirt and bugs at no extra cost." In response, the farmer noted that the sharer's expectations had to come first because they had paid. The farmer asked the crew to be more aware of the quality of produce they were putting in peoples' shares. The degree to which the crew changed its method was negligible, because of the labor involved in looking over each leaf of lettuce for bugs.

Farm staff volunteers, family, and paid staff alike also regularly talked shop about whether the CSA model, as compared to others, was worthwhile. The dedicated volunteers allied themselves with the farmer's spouse and argued that SRT should focus more on selling to restaurant clients because they pay better and they involve fewer individuals' desires and tastes to manage. Because of the farmer's easy-going, inclusive approach to the operation, volunteers found themselves with a lot of latitude in shaping how the farm runs - from whether to wrap beets in paper towels to how much energy to put into the CSA versus other markets. Overwhelmed by trying to accommodate sharers' expectations and schedules, the farmer dropped the CSA component for the 2013 season and has aggressively pursued restaurant markets.

\section{Discussion: Making CSA}

How do these CSAs come to differ and to what end? CSAs vary widely in many ways, but these cases especially demonstrate the importance of how farmers have to choose how to find and manage labor, navigate the seasonality of crop production, and responding to and create expectations in their sharers. These are themes well-known to agro-food scholars in general, but how they play out in CSA matters. These farms' differently scaled commodity practices is a prerequisite to judging how those working for a better agriculture might be "hitching wagons to the wrong stars" (DeLind 2011).

\subsection{Labor}


First, farmers must find and manage the labor necessary to produce and distribute crops to shareholders. The farmers themselves are usually the first to work. All of the CSA farmers discussed here worked at least sometimes in the field and very often were found in the office. At LRF, the farmer spent less time weeding and harvesting and instead focused more on making calls and sending emails to source and distribute produce from other farms. He was aided by a couple of workers based in the share pick-up city, including an office manager and truck driver. The SRCSA and STF farmers were also in the office a lot but regularly contributed to harvesting. Choices about what kind of labor to deploy contributed to differently scaled local food commodities. LRF's extensive organizational scope ranging from skilled migrants specializing in field work, interns who could harvest and pack, and a farmer-manager who could make deals was essential to being able to deliver nearly 500 shares a week packed with produce from multiple sources. The spotty reliability of volunteers, as the SRCSA farmer notes, limits what can be done. At SRT, tight volunteer schedules forced the farmer to concentrate all of the harvest work to one day and thus limited her ability to expand the scope and size of the CSA. The implication is that by employing wage labor CSAs can develop a greater scale of production and exchange.

Hybridity, however, is the rule. There is no necessary connection between the Wisconsin farm's use of hourly wage laborers and its extensive scale of operation. Scaling-up can occur with various kinds of labors. The fact that the 1,000 members run a volunteer-only CSA elsewhere in Wisconsin suggests that wage labor is not a prerequisite to deepening the organizational scope of a farm or extending the spatial reach of it operation. Different farms can also organize similar kinds of labor to different ends. At LRF, interns were a crucial ingredient in the mix. At SRT, volunteers are not just working for their own keeps as they often were at 
SRCSA. They are working to produce crops that the farmer might ultimately decide to sell to high-end restaurants or grocery stores. Labor is a farm-specific response that does not necessitate a specific scale of local food production and exchange go alongside with it. Labor management as a commodity practice is constitutive of different kinds of local food operations.

\subsection{Seasonality}

The CSA farmers also had to respond to weather patterns and the seasonal nature of crop production. They did so in both parallel and divergent ways. More so than the other farms discussed here, the LRF farmer worked hard to fill each box every week and to ensure that shares for different distribution sites were comparable, even when the limited on-farm harvest made it difficult to do so. Bad weather that year sent the farmer searching elsewhere - to other farms who had managed better or were on better ground. For LRF, the motive was to make any one of its shares equivalent to another and to be similarly sized (full) over the course of the season. The drive to fill shares expanded the spatial extent of the farm's operations as well as the scope of organization it took to get produce from grower and eater. The Kentucky and Iowa farms, not supplying any or much produce from other farms, tended to operate on a spatial extent more specific to their own farms and within a scope where the relation between grower and eater was less mediated by auction managers or aggregators.

At the same time, aggregating crops from other farms for a CSA box can be profitable to partner farms. The produce that LRF purchased at auctions and from aggregators was not available to the farm that year because of the weather, but it was not seeking out crops beyond 30 miles of the farm. It did not get crops that would be unseasonal to its location. SRCSA extended its own season by directing members to another area grower who could use his piece of land to raise fall crops. In this way, farms scale their local food products differently in managing 
seasonality. SRCSA sent its members elsewhere to other farms while LRF brought different farms to its members. Both expanded the spatial extent and organizational complexity of their business. In these different commodity practices, both have the idea of increasing the benefits of localized production in mind.

Hoophouses also feature prominently in helping farmers rework notions of what counts as seasonal. Thanks to an NRCS program, the farms are now able to produce crops on-site during times they would not normally have been able to. For the Kentucky farm, a hoophouse and exceptionally warm weather meant greens were seasonal throughout the winter of 2011-2012. Still, how the farms mobilize the productive qualities of a hoophouse varies. SRCSA used theirs more or less entirely for CSA customers, while STF employs it equally for sharers, restaurant, and coop customers. CSAs expand definitions of what is in season while also potentially expanding marketing opportunities. These new opportunities enact a larger organizational scope for the enterprise beyond CSA, one that includes restaurants and grocery stores where consumers are not purchasing directly from the farmer. At the same time, hoophouse production focuses food production more on the farm itself, narrowing the spatial extent of farm operations. Overall, the way farms practice seasonality scales each one in divergent ways as well as variously between each other.

\subsection{Expectations}

Finally, CSA farmers and staff spent much of their time engaged in a balancing act of shareholders' tastes and farm production possibilities. Farmers have to choose whether and how to educate their customers about the farm-specific nature of these issues and the farms discussed here do it in different ways. Different teaching styles are productive of different kinds of food commodities and scales. 
How farms figure out what counts as seasonally local is part of farmers' shaping of sharers' expectations. In using hoophouses for extended-season production, all farms have reworked definitions of local. When LRF built its hoophouse it could expand its own on-farm production and rely less on its partners or auction participants. The farm still sent all of the produce four hours away, but LRF's newsletters evoked a sense of local that meant grown by a small-scale farmer and distributed to the shareholder by someone they know of. SRCSA and $\mathrm{STF}$, on the other hand, were able to play on their relative proximity and connection to their customers, be it through STF's on-farm pickups or, as at SRCSA, by emphasizing the direct relationship between the sharer and the grower. While the analysis here does not incorporate sharers' reception of these ideas, the point is that with the help of newsletters and farm visits farmers worked to produce local food commodities that embedded different senses of locality. The three CSAs come to be scaled differently in part by how farmers represent the localness of their products to their sharers.

CSA farmers also have to deal with sharer expectations about how much food they will receive and what condition it will be in. LRF believed that sharers needed to see a full box each week and so at no small expense sought out produce from other farms. At STF as well, the farmer was concerned about providing an abundant share, but felt that her on-farm production was adequate and had stopped buying produce from an auction. SRCSA did not box sharers' produce and since there was no good metric (i.e. a full box did not make sense since everyone brought their own) - and because of the farm's longevity and the farmer's confidence in having taught farm operations to customers - the conversation about adequacy was minimal. But the farmer saw some vegetables, like the green onions, as needing intimate cleaning before being shipped to the pick-up sites. The same is the case for STF, where, for instance, the crew chose to 
spent significant extra time adding paper towels to produce in order to help it retain moisture. Taking the time to wash and wrap vegetables diverts precious crew time from other pressing activities like weeding and from expanding production in general. A choice to fill boxes sent LRF to other farms for produce, while the practice of carefully washing produce limits other productive work that can be done at SRCSA and STF. Each manner of dealing with customer expectations reworked the spatial extent and organizational scope of each CSA differently.

The choices that each farm has to make about labor, seasonality, and educating shareholders are contextual ${ }^{6}$. They are not made in a vacuum without reference to what's possible and socially acceptable in a given region. Sometimes these contexts differ between farms and sometimes they turn out to be similar. The labor choices available to LRF are different to those available to STF. STF is nearer to an immigrant community and potential workforce, though she has chosen not to hire from this population. But LRF is able to recruit migrant labor seasonally, a practice not uncommon in the area. Consumers differ from place to place as well. Shareholders living in the area that SRCSA serves are more attuned to the ins and outs of local food than those in the community STF sells to partly because of the work of area farmers to educate their members and the general public (Lyson 2004; Janssen 2011) and partly because of different income and education levels. Competitors and partner producers differ between contexts. LRF is well-connected to other experienced and established growers in the area who have been at the forefront of the organic and local food movements nationally. The kind of scale of LRF is typical of the area with many similar enterprises selling produce to major markets. These sorts of factors put a frame around how each farm manages labor, seasonality, and shareholder expectations.

\section{Conclusion}


Each farm I have looked at here scales production and exchange relations in a hybrid fashion. LRF develops an extensive organizational scope by employing a mix of wage and seasonal labor to bring shareholders produce purchased from other farms and acquired through an auction. It increases its spatial reach by sourcing from partner farms to manage shareholder expectations. But LRF now also emphasizes on-farm production with its own hoophouse. At SRCSA and STF, farmers increased on-farm production with hoophouses as well and they pursued more direct interactions with shareholders. But both have also sourced from partner farms. All the farms also scale differently between one another. In general, at LRF the CSA commodity travels farther, comes from multiple farms, and shareholders do not meet the grower, while at SRCSA and STF, the farmers and food are symbolically and materially more wellknown.

The overlapping, yet differing practices of putting labor to use, responding to weather and climate, and managing sharer expectations, ultimately constitute uniquely scaled local foods commodities. Following Mount's (2012) demonstration of already existing hybridity in CSA practice, I argue that the farms' sometimes more scaled-up shares are not - as Delind (2011) or Henderson (2012) would have it - a result or indication of having lost sight of the aims of the local food movement. Although I did not directly investigate whether farms met any social and ecological goals (arguably an unanswerable question), my analysis suggests the CSAs' practices are different farm-based responses that still ally with local foods advocates' aims.

I will note two caveats. First, I have examined CSA because it is historically a key component of the local food experience (Henderson and Van En 1999) and is an evolving institution. Food hubs, however, are an emerging local food institution that raise similar questions. Food hubs aggregate produce from multiple farms and then distribute the produce to 
customers - or sharers when it is run in a CSA format - but hubs are generally not farm-based (Barham 2010). Future research should look at the choices food hubs make when it comes to dealing with customer or sharer expectations and the labor and seasonality relationship they form with their partner farms. Second, I have largely set aside the sharer perspective in this paper. In some CSAs, sharers are still intimately involved in farm governance, but they were not so much in these cases. How do sharers respond to new kinds of CSAs where their formal involvement may be limited and produce may come from multiple farms? Will this risk CSA losing legitimacy? In order to answer it, we must first understand how and why farms come to scale differently.

CSA has certainly changed much since DeLind $(1999,8)$ "wonder[ed] if a CSA [could] be individually owned." My point has been to use the commodity practice lens to interrogate the art of scaling-up a market in a good whose value depends on socio-ecological context. The lens can be a good framework for future work that investigate emerging forms of local foods exchanges in CSAs, food hubs, and other institutions and their consequences. It will be useful for scholars who wish to examine, say, farms' use of hoophouses to extend production without having to see this as risk-hedging, but instead as how farms give crops "added" value as meaningful commodities. Commodity practice will also illustrate the diversity of ways farms within the local foods movement come to scale their operations. Commentators should first grapple with the nature of this diversity before passing judgment.

Notes

1. A greenhouse is a more permanent structure often made with glass panels and sometimes heated, while a hoophouse is made with polyethylene plastic and unheated

2. Geographers actually make important distinctions between the kinds of scale I am describing here, that is, between scale as spatial reach rather than levels of social organization (e.g. "the household") (see the discussion in Marston et al. 2005). The 
distinction is one that often goes unremarked in the scaling-up discussion. I adopt these terms of the debate because my critique is meant to be an immanent one. Even if commentators confuse scale as particular spatial extents associated with certain forms of social organization (e.g. small scale as the domain of the household), the conversation need not lament scaled-up farm practices, because scaling is hybrid. What helps me in this is that rather than assuming a level of social organization like the household already exists, I show that it is practiced. I am indebted to Tad Mutersbaugh for helping me to clarify this point.

3. Farm names are pseudonyms.

4. The funding mechanism, which falls under the USDA's umbrella "Know Your Farmer, Know Your Food" program, is designed to encourage soil conservation (by encouraging small-scale greens production in place of bare soil or intensively tilled crops) and grow farmer incomes.

5. Yet other farms, though less common allow members to choose exactly what produce they receive, usually at farmers markets. Galt et al. (2011) call this the "Farm Membership/Share Model."

6. I am indebted to one of the anonymous reviewers for bringing this point to my attention.

\section{References}

Alkon, A.H., 2008. From value to values: Sustainable consumption at farmers markets, Agriculture and Human Values 25, pp. 487-498.

Allen, P. and Kovach, M., 2000. The capitalist composition of organic: The potential of markets in fulfilling the promise of organic agriculture, Agriculture and Human Values 17, pp. 221-232.

Barham, J., 2010. Getting to scale with regional food hubs. USDA blog. http://blogs.usda.gov/2010/12/14/getting-to-scale-with-regional-food-hubs/ Accessed 3 January 2013.

Born, B. and Purcell, M., 2006. Avoiding the Local Trap: Scale and Food Systems in Planning Research, Journal of Planning Education and Research 26 (2), pp. 195-207.

Bryant, R.L. and Goodman, M.K. 2004. Consuming narratives: the political ecology of "alternative" consumption, Transactions of the Institute of British Geographers 29 (3), pp. $344-366$. 
Castree, N., 2003. Commodifying what nature? Progress in Human Geography 27 (3), pp. 273293.

Cone, C.A. and Kakaliouras, A., 1995. Community Supported Agriculture: Building Moral Community or an Alternative Consumer Choice, Culture \& Agriculture (51/52), pp. 2831.

Cook, I. and Crang, P., 1996. The World On a Plate: Culinary Culture, Displacement and Geographical Knowledges, Journal of Material Culture 1 (2), pp.131-153.

Cronon, W., 1992. Nature's Metropolis: Chicago and the Great West, W. W. Norton \& Company, New York.

de Janvry, A., 1982. The Agrarian Question and Reformism in Latin America, Johns Hopkins University Press, Baltimore.

DeLind, L., 1999. Close Encounters with a CSA: The Reflections of a Bruised and Somewhat Wiser Anthropologist., Agriculture and Human Values 16, pp. 3-9. , 2003. Considerably More than Vegetables, A lot Less than Community: The Dilemma of Community Supported Agriculture. In: Fighting for the Farm: Rural America Transformed, ed. J. Adams, 192-206, University of Pennsylvania Press, Philadelphia. , 2010. Are local food and the local food movement taking us where we want to go? Or are we hitching our wagons to the wrong stars? Agriculture and Human Values 28 (2), pp. 273-283.

DuPuis, M.E. and Goodman, D., 2005. Should we go "home" to eat?: toward a reflexive politics of localism, Journal of Rural Studies 21, pp. 359-371.

Fraser, A., 2010. The craft of scalar practices, Environment and Planning A 42(2), pp. 332-346. 
Fromartz, S., 2007. Organic, Inc.: Natural Foods and How They Grew, Harcourt, Orlando, FL.

Galt, R.E., Beckett, J., Hiner, C.C., and O'Sullivan, L., 2011. Community Supported Agriculture (CSA) in and around California's Central Valley: farm and farmer characteristics, farmmember relationships, economic viability, information sources, and emerging issues. http://hcd.ucdavis.edu/faculty/webpages/galt/personal/Galt_Faculty_Page/CV_files/Galt \%20et\%20al.\%202011-CSA\%20Report.pdf Accessed 17 August 2012.

Gibson-Graham, J. K., 2006. The End Of Capitalism (As We Knew It): A Feminist Critique of Political Economy, 1st ed. Univ Of Minnesota Press.

Goland, C., 2008. Community Supported Agriculture, Food Consumption Patterns, and Member Commitment, Culture and Agriculture 24(1), pp. 14-25.

Goodman, M.K., 2004. Reading fair trade: Political ecological imaginary and the moral economy of fair trade foods, Political Geography 23 (7), pp. 891-915.

Guthman, J., 1998. Regulating Meaning, Appropriating Nature: The Codification of California Organic Agriculture, Antipode 30 (2), pp.135-154. , 2004. Agrarian Dreams: The Paradox of Organic Farming in California, University of California Press, Berkeley.

Harris, E.M., 2009. Neoliberal subjectivities or a politics of the possible? Reading for difference in alternative food networks, Area 41 (1), pp. 55-63. 2012. Practicing Local Eating: Sustainability in Place in Fife, Scotland. Talk delivered at Association of American Geographers annual meeting, February 2012, New York, NY.

Harvey, D., 1990. Between Space and Time: Reflections on the Geographical Imagination, Annals of the Association of American Geographers 80 (3), pp. 418-434. 
Henderson, E., 2012. Farm-connected CSAs should offer more than just 'veggie subscriptions.' Grist.org http://grist.org/locavore/csa-just-a-vegetable-subscription-or-a-way-to-trulyconnect-with-your-farm/ Accessed 17 August 2012.

Henderson, E. and Van En, R., 1999. Sharing the Harvest: A Citizen's Guide to Community Supported Agriculture, Chelsea Green Publishing Company, White River Junction, VT. Henderson, G., 1998. Nature and Fictitious Capital: The Historical Geography of an Agrarian Question, Antipode 30(2), pp. 73-118.

Hinrich, C.C., 2000. Embeddedness and local food systems: notes on two types of direct agricultural market, Journal of Rural Studies 16(3), pp. 295-303. , 2003. The practice and politics of food system localization, Journal of Rural Studies 19 (1), pp. 33-45.

Holloway, L. and Kneafsey, M., 2000. Reading the space of the farmers' market: a preliminary investigation from the UK, Sociologia Ruralis 40 (3), pp. 285-299.

Jarosz, L., 2000. Understanding agri-food networks as social relations, Agriculture and human values $17(3)$, pp. 279-283.

Janssen, B., 2010. Local Food, Local Engagement: Community-Supported Agriculture in Eastern Iowa, Culture and Agriculture 32(1), pp. 4-16.

Lang, K.B., 2010. The Changing Face of Community-Supported Agriculture, Culture and Agriculture 32(1), pp. 17-26.

Lyson, T.A., 2004. Civic Agriculture: Reconnecting Farm, Food, and Community, University of New England Press, Lebanon, NH.

Mann, S.A. And Dickinson, J., 1978. Obstacles to the Establishment of a Capitalist Agriculture, Journal of Peasant Studies 5, pp. 466-481. 
Mansfield, B., 2005. Beyond rescaling: reintegrating the national as a dimension of scalar relations, Progress in Human Geography 29(4), pp. 458-473.

Marston, S., Jones III, J.P., and Woodward, K., 2005. Human geography without scale, Transactions of the Institute of British Geographers 30(4), pp. 416-432.

Marx, K., 1976 [1867]. Capital Volume 1, Penguin, London.

McFadden, S. The History of Community Supported Agriculture. http://newfarm.rodaleinstitute.org/features/0104/csa-history/part1.shtml Accessed 17 August 2012.

Mooney, P.H., 1982. Labor Time, Production Time, and Capitalist Development in Agriculture; A Reconsideration of the Mann-Dickinson Thesis, Sociologia Ruralis 22(3-4), pp. 279-292.

Mount, P., 2012. Growing local food: scale and local food systems governance, Agriculture and Human Values 29 (1), pp.107-121.

Murdoch, J, Marsden, T., and Banks, J., 2000. Quality, nature, and embeddedness: some theoretical considerations in the context of the food sector, Economic geography 76(2), pp. 107-125.

Nabhan, G.P., 2002. Coming home to eat: the pleasures and politics of local food, W.W. Norton, New York.

Perez, J., Allen, P., and Brown, M., 2003. Community Supported Agriculture on the Central Cost: The CSA Member Experience, Center for Agroecology and Sustainable Food Systems http://escholarship.org/uc/item/5wh3z9jg Accessed 17 August 2012.

Pollan, M., 2006. The omnivore's dilemma: A natural history of four meals, Penguin Group.

Rigby, D. and Bown, S., 2007. Whatever Happened to Organic? Food, Nature, and the Market for 'Sustainable' Food,Capitalism, Nature, Socialism 18(3), pp. 81-102. 
Robertson, M., 2000. No net loss: wetland restoration and the incomplete capitalization of nature. Antipode 32(4): 463-493 ,2011. Measurement and alienation: making a world of ecosystem services, Transactions of the Institute of British Geographers, 37, pp. 386-401.

Sage, C., 2003. Social embeddedness and relations of regard: alternative 'good food' networks in south-west Ireland, Journal of Rural Studies 19(1), pp. 47-60.

Smithers, J., Lamarche, J., and Joesph, A.E., 2008. Unpacking the terms of engagement with local food at the farmers' market: Insights from Ontario, Journal of Rural Studies 24, pp. 337-350.

Trauger, A. and Catarina P., 2012. Towards a post-capitalist-politics of food: cultivating subjects of community economies, ACME: An International E-Journal for Critical Geographies 11(2), pp. 282-303.

United States Department of Agriculture (USDA), 2011. Know Your Farmer Know Your Food. http://www.usda.gov/documents/KYFCompass.pdf Accessed 16 August 2012.

Winter, M., 2003. Embeddedness, the new food economy and defensive localism, Journal of Rural Studies 19, pp. 23-32. 